\title{
Spared, shared and lost—routes for maintaining the Scandinavian Mountain foothill intact forest landscapes
}

\author{
Johan Svensson $^{1}$ (D) Jakub W. Bubnicki ${ }^{2} \cdot$ Per Angelstam ${ }^{3,4} \cdot$ Grzegorz Mikusiński $^{5} \cdot$ Bengt Gunnar Jonsson $^{1,6}$
}

Received: 30 June 2021 / Accepted: 16 January 2022 / Published online: 2 March 2022

(c) The Author(s) 2022

\begin{abstract}
Intact forest landscapes harbor significant biodiversity values and pools of ecosystem services essential for conservation, land use and rural development. Threatened by fragmentation and loss by transitions to industrial clear-cut forestry, those landscapes are of pivotal interest for protection that secures their intact character. With wall-to-wall land-cover data, we explored opportunities for maintaining intact forest landscapes through comprehensive spatial planning across a 2.5 million hectares boreal to sub-alpine forest region along the eastern slopes of the Scandinavian Mountain range. We analyzed forest and woodland types that are protected, need protection or potentially can be subject to continued forest management. We established that the fraction of already clear-cut forest is very small and that the forest landscape of the Scandinavian Mountain foothills contains a high proportion of protected high conservation value forests, covering almost 2 million ha, and that over 500,000 ha (27\%) remains unprotected and may be subject to future protection or continued adapted forest management. We found evident north to south differences with respect to forest landscape configuration, distribution of unprotected forests and land ownership. With a focus on non-industrial private landowners, we conclude that sustainable land-use requires integrative, multi-functional approaches that rely on further protection, forest and forest landscape restoration and a much larger share of continuous cover forestry than presently. Our results provide input into ongoing policy implementation and green infrastructure planning in the context of securing intact forest values and integrative opportunities for rural livelihood and regional development based on multiple value chains.
\end{abstract}

Keywords Biodiversity · Green infrastructure · Multiple use · Scandinavian Mountains Green Belt · Rural development

Communicated by José Valentin Roces-Diaz.

Johan Svensson

johan.svensson@slu.se

1 Department of Wildlife, Fish and Environmental Studies, Swedish University of Agricultural Sciences (SLU), 90183 Umeå, Sweden

2 Mammal Research Institute Polish Academy of Sciences, Division of Population Ecology, Białowieża, Poland

3 Present Address: School for Forest Management, Swedish University of Agricultural Sciences (SLU), 73921 Skinnskatteberg, Sweden

4 Department of Forestry and Wildlife Management, Inland Norway University of Applied Sciences, Campus Evenstad, N-2480 Koppang, Norway

5 Department of Ecology Grimsö Wildlife Research Station, School for Forest Management, Swedish University of Agricultural Sciences (SLU), 73091 Riddarhyttan, Sweden

6 Department of Natural Sciences, Mid Sweden University, 85170 Sundsvall, Sweden

\section{Introduction}

The rare remnants of contiguous forest-dominated landscapes and mosaics of forests and associated open and semiopen land-cover types with high degrees of naturalness are crucially important since they harbor capacity for climate change mitigation and adaptation, biodiversity conservation and multiple ecosystem services (Thom et al. 2019; Sabatini et al. 2020; Ward et al. 2020). With the pronounced human footprint on nature globally (Venter et al. 2016; Bar-on et al. 2018), there is an increasing concern that the comprehensive and diverse values of the last remaining intact forest landscapes (Potapov et al. 2017) will deteriorate further (Jones et al. 2018; Watson et al. 2018; Zanotti and Knowles 2020). Expanding frontiers of clear-cut forestry (e.g. Seedre et al. 2018; Angelstam and Manton 2021) into such areas is a main cause of forest and biodiversity loss worldwide (Mikusiński et al. 2018; Venier et al. 2018; Mikoláš et al. 2019; Betts et al. 2021). More ambitious conservation 
strategies and targets are therefore promoted (e.g. Ward et al. 2020, EU, 2020). For example, active restoration of intactness and naturalness (e.g. Watson et al. 2018) and multiple value chains that better maintain the multi-facetted values of forest landscapes (e.g. Angelstam et al. 2020) have become adopted at international and national levels (e.g. CBD zero draft 2020; EU 2020, 2021; SOU 2020).

Intact forest landscapes are invaluable for their intrinsic values for in-situ conservation, for observing forest ecosystem responses to climate change and expansive land use, and as reference areas for forest landscape restoration (Angelstam et al. 2011; Kuuluvainen et al. 2017; UN 2019). They further represent "mainland" areas with viable species populations that can disperse into adjacent fragmented and transformed forests, landscapes and regions. Hence, their maintained "ecological memory" (Bengtsson et al. 2003) can support and strengthen functional green infrastructure (European Commission 2013) in forest landscapes (Pickett and Cadenasso 2018; Slätmo et al. 2019; Svensson et al. 2020a). Thereby, remaining intact forest landscapes and other geographically larger components of natural and semi-natural forests represent the nodes onto which regional planning for functional ecological networks of protected forests should be built (e.g. Ward et al. 2020; Mikusiński et al. 2021).

As forests and forest landscapes in Europe have been largely transformed during the twentieth century era of industrial forest management, old-growth and naturally dynamic forests are rare or missing and, consequently, recognized as priority conservation entities (Sabatini et al. 2018; Angelstam et al. 2021). This is recognized in the EU 2030 Biodiversity Strategy (EU 2020/21) which has set a target of $30 \%$ protection whereof a third with strict protection, with the protected areas forming ecologically functioning networks. Furthermore, intact forest landscapes are integrated into the Forest Stewardship Council (FSC) certification standards with direct consequences for forest management policies worldwide (Blumroeder et al. 2019; Kleinschroth et al. 2019). Accordingly, and for example with reference to the European primary forest database (Sabatini et al 2021), remaining intact forest landscapes need to be identified, mapped and assessed regarding opportunities and threats to maintain their full range of values in the view of national and pan-national environmental targets, e.g. the Aichi targets (CBD 2010), the EU biodiversity strategy and national policies.

The foothills forest landscape of the Scandinavian mountain range, i.e. the "Scandinavian Mountains Green Belt" (SMGB; Svensson et al. 2020a), includes a significant portion of the remaining intact forest landscapes in Europe (Potapov et al 2008a, b; Heino et al. 2015; Curtis et al. 2018; Sabatini et al. 2021). Due to a more strict legal regulation of clear-cutting forestry in the foothills forests above the mountain forest border (Jonsson et al. 2019), these hinterland forest landscapes harbor intact forest landscape qualities (Svensson et al. 2019; Svensson et al. 2020a; Mikusiński et al. 2021). For the term intact forests, we here follow the definition by Potapov et al. (2008a, b, 2017) as larger (> 500 $\mathrm{km}^{2}$ ) mosaics of forests and natural open ecosystems that include primary forests and shows no or low influence of human activities and habitat fragmentation, but where some historic human influence of, e.g. preindustrial selective tree felling, may have occurred. Primary forests are defined as naturally regenerated forest with native tree species, no clearly visible signs of human interference and where the ecological processes are not significantly disturbed (FAO 2020). Thus, primary forests constitute cores within intact forest landscapes, which conservation status is amplified by their intact surroundings of other forests and other landcover types.

In the Swedish mountain region, encompassing the foothills forests and the subalpine and alpine areas above the mountain forest border, close to 1.5 million ha of forests and forest-dominated landscapes are formally protected, amounting to $62 \%$ of all formally protected forests in Sweden (Statistics Sweden 2021). Recently, a forest policy inquiry (SOU 2020) proposed additional protection of the remaining high conservation-value forest areas, which would result in $80 \%$ protection of the total mountain forestland area. However, a high conservation ambition of the SMGB may not necessarily exclude continued forest landscape use that supports diverse value chains built on material and immaterial values (Jonsson et al. 2019). To achieve sustainability in this region and to meet multiple land-use demands, however, future conservation and land-use strategies require a knowledge base that ensures the integrity and resilience of the intact forest values in the context of integrative planning approaches to multiple value chain (e.g. Aggestam et al. 2020; Bollmann et al. 2020).

This study focused on the amount, spatial distribution and characteristics of forests and woodlands located in the Swedish mountain region. We categorized forests and woodlands based on their conservation status into categories that represent key landscape planning components that need to be taken into account in implementing high conservation ambitions, while at the same time reflect multiple-use opportunities and multiple value chains. The aim was to establish a planning basis that ensures maintained intactness of the SMGB based on what is spared or should be spared, i.e. current and future protection, and what could be shared with multi-objective integrative or segregative land-use strategies and adjusted to conservation needs. To achieve this, we analyzed up-to-date and wall-to-wall spatial datasets of forest types, conservation values and land ownership, and discuss how their distributions can guide planning at different spatial scales, particularly concerning forests that may be subject to 
future clear-cutting. As such, we on the one hand provide an illustrative case on the challenges to ensure the integrity and values of intact forest landscapes of European significance, and on the other hand to support multiple-value based rural development in a rural, hinterland region. We foresee that this study will contribute to clarify premises for fulfilling international and national agreements on protecting outstanding ecosystems, biodiversity and ecosystem services in northern boreal and subalpine forest landscapes.

\section{Material and methods}

\section{Study region}

This study focuses on a 8.9 Mha territory of the Swedish mountain region (Swedish Forest Agency 1991), which was divided into four sub-regions, here termed "far south", "south", "central" and "north" (Fig. 1) following Roberge (2018). "Far south" (c. 0.9 Mha terrestrial surface; Dalarna County and the two southern municipalities in Jämtland County) is characterized by a dominance of Scots pine (Pinus sylvestris) forests and a forest floor dominated by ground lichens. "South" (c. 1.1 Mha; the three northern municipalities in Jämtland County) is characterized by a dominance of Norway spruce (Picea abies) forests, herb-rich forest floors, calcium-rich parent material and an Atlantic macroclimate. "Central" (c. 1.6 Mha; Västerbotten County) is dominated by spruce forests but with less favorable macroclimatic conditions and less fertile soils. "North" (c. 5.3 Mha; Norrbotten County) is characterized by a dominance of pine forests, forest floors dominated by ground lichens, low annual temperature and short vegetation periods, large wetland areas and postglacial sediments.

The general bioclimatic constraints at higher altitudes and latitudes cause a large share of forests and woodlands with low site fertility often resulting in a semi-open woodland character. With increasing altitude the forests gradually transform from conifer dominated to deciduous woodland with mountain birch (Betula pubescens ssp. czerepanovii) forming the alpine tree line (Hedenås et al. 2016), but with increasing occurrence of pine in the south and north. Thickets of dwarf birch (Betula nana), willows (Salix spp.) and ericaceous shrubs cover large proportions of concave and locally low-lying terrain and are gradually replaced by heaths and barren land at higher altitude.

The Swedish mountain region has hinterland, rural characteristics with low human population and less developed urban facilities, social services and road networks (Statistics Sweden 2019). Traditional small-scale forestry and mountain farming have declined, while industrial clear-cut forestry is maintained but at decreasing level since the 1990s (Jonsson et al. 2019). Tourism and outdoor recreation contribute to local livelihood, with both more developed facilities and nature-based wilderness adventures. Wind- and hydro-power production facilities and mines occurs and have significant impact in certain places (Jansson et al. 2015; Svensson et al. 2020b). A unique feature is the indigenous Sami people culture and reindeer (Rangifer tarandus) husbandry that contribute substantially to the comprehensive and diverse landscape values (Blicharska et al. 2017). The state is the dominating landowner, but also private forest incorporates, forest commons and non-industrial private ownership occur.

\section{Data and analysis}

With a focus on forests and forest landscapes, this study is based on the most recent remote sensing-generated landcover data, inventories of high conservation value forests and mapping of not clear-cut forests. We applied the most recently updated (Swedish EPA 2019) high-resolution $(10 \times 10 \mathrm{~m}$ raster) national land-cover data $(\mathrm{NMD})$ for the areal coverage and spatial distribution of different forest types and woodland areas. We followed the NMD classification of forest types based on dominating $(\geq 70 \%)$ tree species with distinction between forests located on high and low productivity sites (division based on site capacity to support tree growth $\geq 1 \mathrm{~m}^{3} \mathrm{ha}^{-1}$ per year over a rotation cycle, and applying the terminology used by Hämäläinen et al. 2019). Economic-oriented forestry is Sweden is legally restricted to high productivity sites following the above definition and thus this division is relevant as a proxy for assessing actual and potential clear-cut forestry. The forest types included in the analysis were pine forest, spruce forest, mixed coniferous and deciduous (mainly mountain birch and hairy birch; Betula pubescens) forest and pure deciduous forest. We also included recently clear-cut forest areas and woodlands ( $<5 \mathrm{~m}$ height mountain tree and shrub vegetation on wetland and other semi-open land cover) also using the NMD data.

We applied data on proxy continuity forests (pCF; Ahlcrona et al. 2017; Svensson et al. 2019), i.e. mature and old forests not systematically clear-cut during at least the last c. 70 years). Given the late establishment of systematic clear-cutting forestry in this region (Kuuluvainen et al. 2017), large proportions of the pCF have thus not experienced systematic clear-cut forestry with transition to even-aged systems (Svensson et al., 2019). For delineating forests with confirmed significance for biodiversity conservation, we applied the high conservation value forest (HCVF) dataset (Anon 2017) and added the recent (2020) inventory data which was performed specifically as input to the mountain forest section of the forest policy inquiry (SOU 2020; Henriksson and Olsson 2020). The $\mathrm{HCVF}$ areas were further separated into protected and unprotected forests using spatial datasets from the Statistics Sweden (2021). 
Fig. 1 (a) The study region (black line) includes the Scandinavian mountain region in Sweden above the mountain forest border with green showing the boreal biome. (b) Land cover with black dashed lines showing the boundaries of the four study sub-regions and with green color showing forests and woodlands, blue showing water bodies and yellow to white to purple showing different open mire and alpine environments. (c) The four forest-type categories assessed: non-pCF, i.e. forestlands that are not mapped as proxy continuity forests; unprotected $\mathrm{pCF}$; unprotected high conservation value forests $(\mathrm{HCVF})$; protected HCVF. Other land cover classes than forest including mountain woodlands are shown in black

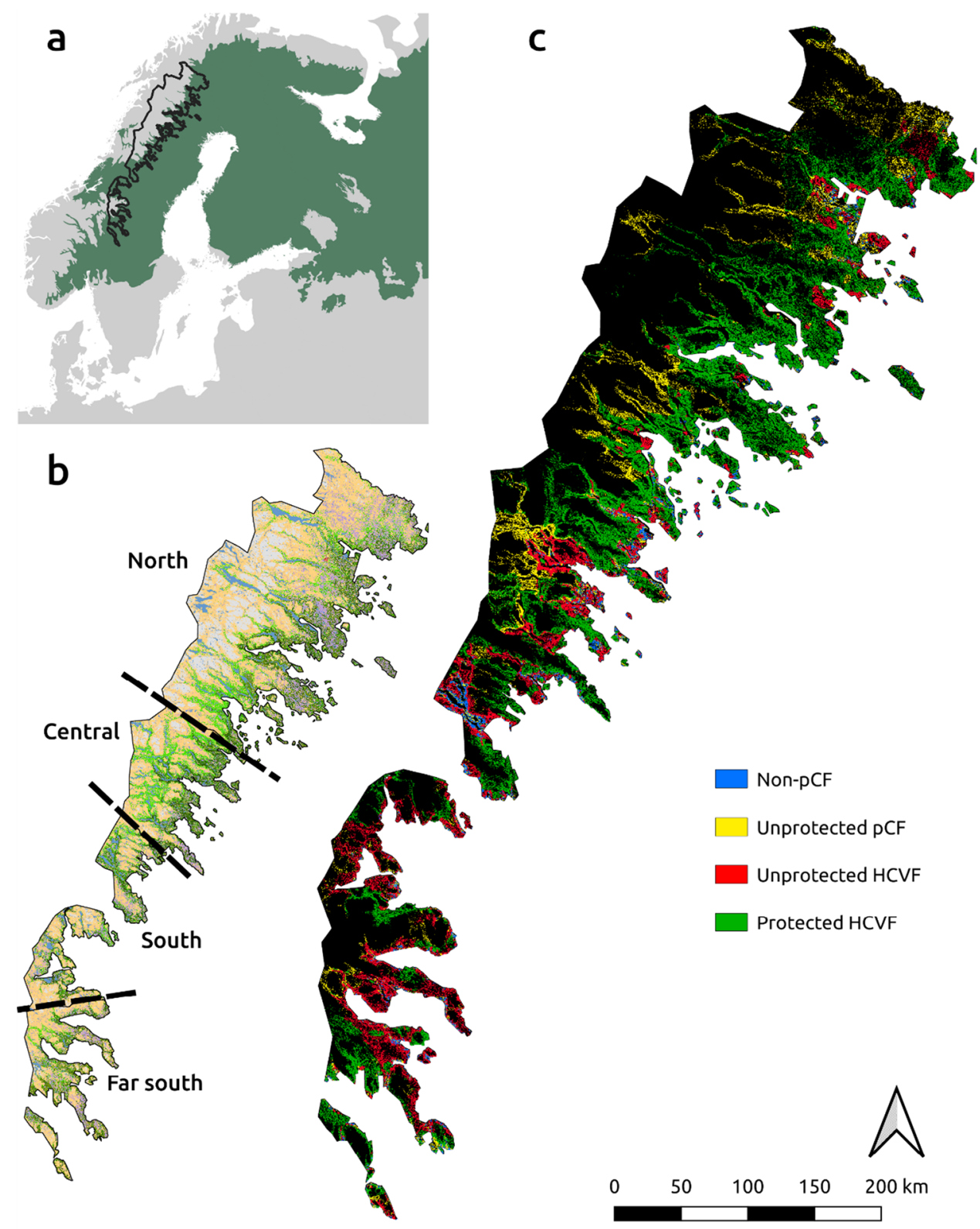

We overlaid the HCVF and pCF datasets to spatially analyze and visualize forest areas of different status. This resulted in four main categories: (1) unprotected HCVF, i.e. not protected forests with known and documented conservation values; (2) unprotected pCF, i.e. not protected forests with not documented, or without, high conservation values; (3) protected HCVF, i.e. already set aside for conservation; and (4) clear-cut forest, i.e. areas classified as recently clear-cut or generally without forest cover (see also supplementary material Figure S1). Here, protected forests are the formally protected areas according to the Swedish Environmental Code, Land Code and State agreements (Statistics Sweden 2021). Thus, voluntary set asides and general consideration areas were not considered. Thereby, the currently unprotected and not previously clear-cut forest areas (categories 1 and 2, i.e. included in the HCVF- and/or pCF-datasets) refer to forest segments that can become subject to either additional protection or to some form of continued forest management.

To assess the distribution and characteristics of forests that are potentially available for forest management, but also with a potential to further strengthen the intact landscape values, we focused the analysis on the high productivity forests outside formal protection. More specifically, we focused on forests that have already confirmed (unprotected HCVF) or possibly harbor (unprotected $\mathrm{pCF}$ ) high conservation values, which were separated into 
Table 1 Total forestland, proxy continuity forests (pCF), forest loss and woodland area (in 1,000 ha) on high and low productivity sites and combined, for all forestland, all high conservation value forests
(HCVF) and protected HCVF (P. HCVF). The data are presented for five main generalized forest types (pine, spruce, mixed and deciduous, and recently logged forests) and in total

\begin{tabular}{|c|c|c|c|c|c|c|c|c|c|}
\hline & \multicolumn{3}{|c|}{ High productivity sites } & \multicolumn{3}{|c|}{ Low productivity sites } & \multicolumn{3}{|l|}{ All sites } \\
\hline & All land & All HCVF & P. HCVF & All land & All HCVF & P. HCVF & All land & All HCVF & P. HCVF \\
\hline \multicolumn{10}{|l|}{ Forestland } \\
\hline Pine & 192.8 & 150.3 & 110.2 & 185.8 & 161.1 & 126.1 & 378.6 & 311.4 & 236.3 \\
\hline Spruce & 519.9 & 471.2 & 303.6 & 174.4 & 162.4 & 130.3 & 694.3 & 633.6 & 433.9 \\
\hline Mixed & 272.9 & 213.6 & 129.0 & 228.8 & 200.1 & 142.7 & 501.6 & 413.7 & 271.7 \\
\hline Deciduous & 55.0 & 30.5 & 13.4 & 839.0 & 579.1 & 480.9 & 893.9 & 609.7 & 494.3 \\
\hline Recently logged & 71.2 & n.a & n.a & 0.3 & n.a & n.a & 71.5 & n.a & n.a \\
\hline Total & 1111.7 & 865.6 & 556.1 & 1428.1 & 1102.7 & 880.1 & 2539.9 & 1968.3 & 1436.2 \\
\hline \multicolumn{10}{|c|}{ Of which pCF of forestland } \\
\hline Pine & 166.3 & 145.5 & 107.8 & 182.4 & 160.2 & 125.7 & 348.7 & 305.8 & 233.5 \\
\hline Spruce & 496.5 & 464.3 & 301.4 & 172.8 & 161.6 & 130.0 & 669.3 & 625.9 & 431.4 \\
\hline Mixed & 233.8 & 205.9 & 126.2 & 224.6 & 198.6 & 142.2 & 458.4 & 404.5 & 268.4 \\
\hline Deciduous & 39.0 & 26.8 & 11.8 & 824.4 & 573.7 & 477.8 & 863.4 & 600.6 & 489.6 \\
\hline Total & 935.6 & 842.5 & 547.3 & 1404.2 & 1094.2 & 875.6 & 2339.8 & 1936.7 & 1423.0 \\
\hline Forest loss & 175.6 & 35.1 & 13.7 & 14.4 & 4.8 & 2.4 & 190 & 39.9 & 16.1 \\
\hline Woodland & 145.7 & 114.7 & 83.7 & 803.3 & 559.3 & 451.9 & 949.0 & 674.0 & 535.6 \\
\hline
\end{tabular}

Footnote: All estimates are derived from the original dataset with $10 \times 10 \mathrm{~m}$ spatial resolution. Area calculations are nested with protected HCVF being a share of all HCVF and all HCVF being a share of all forestland and pCF, respectively. A minor fraction of forestlands that are not pCF, i.e. recently logged forests has been classified as HCVF. This is likely an effect of using independent spatial data as recently logged is provided by NMD (Metria 2019), pCF (Ahlcrona et al. 2017), HCVF (Anon 2017) and Henriksson and Olsson (2020)

forest types, patch-size classes and landowner categories for each of the sub-regions. For landownership, we used data provided by the Swedish Environmental Protection Agency (Henriksson and Olsson 2020). We separated land owners into three categories: (i) public-including the state Property Board, Swedish Environmental Protection Agency (formally protected areas), Fortification Agency, municipalities and administrative region units; (ii) private incorporates-including private forest industry companies, the state Sveaskog forest company, church and commons (due to their forest-industry behavior in Sweden; cf. Holmgren et al. 2007); and (iii) non-industrial private forest owners (NIPF) — encompassing private person ownership polygons $<1000 \mathrm{ha}$. Here, a polygon is to be understood as one spatial administrative entity, but since ownership can include several polygons, this cannot directly be translated to separate owners. This landowner categorization is applicable on the scale of the study region at state as a generic approach to how forest management is practically exercised in Sweden, but locally as well as over time there is variation within the categories.

We assessed the spatial and patch-size distribution of unprotected pCF and unprotected HCVF forests, on high productivity forestlands for each of the four sub regions and for the entire study region. Using the Python package SciPy Ver. 1.1.0, we identified all forest patches $\geq 1$ ha in an eight-pixel neighborhood structure (i.e. all surrounding pixels around each pixel). The area of pCF-fragments $<1$ ha was estimated using the original $10 \times 10 \mathrm{~m}$ data resolution. We re-sampled the pCF-raster to a coarser grid $(1 \mathrm{ha} ; 100 \times 100 \mathrm{~m})$ through mode-based aggregation ( $\geq 50 \% \mathrm{pCF})$. A rasterized land-ownership vector layer was used to analyze the distribution of unprotected high productivity forests for different patch-size classes and forest types for each ownership category and for all sub-regions.

\section{Results}

Forestlands above the mountain forest border (Fig. 1) cover in total 2.54 million ha, of which $56.5 \%$ is formally protected (Table 1 ). Woodlands cover an additional 950,000 ha. High conservation value forests cover almost 2 million ha, whereof $73 \%$ are protected. Deciduous forest is the most abundant forest type across all forestland (35\%) and all protected HCVF (34\%), followed by spruce forests (27\% and $30 \%$, respectively). Low productivity sites cover a larger proportion of forestlands $(56 \%)$ than high productivity sites, especially for protected HCVF. For high productivity forests, both in total and for protected HCVF, spruce dominates followed by mixed forests and pine forests. Almost all forestland is pCF (92\%), where the protected share is slightly higher than for all forestland 
$(61 \%)$ as well as for high (58\%) and low $(62 \%)$ productivity forestland. A very large share $(83 \%)$ of the pCF are also HCVF. Forest loss, mainly including recently clearcut forests, is minor (190,000 ha) and almost exclusively occurs on high productivity sites: $7 \%$ of all forestland and $19 \%$ of high productivity sites.

Generally, pCF on high productive forestlands occur in the vicinity of the mountain forest border and in the river valleys to the west (Fig. 2), thus following lower altitude terrain. Overall, the distribution of $\mathrm{pCF}$ is contiguous in the north and central sub-regions, but fragmented in the south and far south sub-regions. Pine forests show a disjunct distribution with high abundance in the north and far south sub-regions. Spruce and mixed forests are more contiguous, and deciduous forests are more widespread and most abundant in the central and north sub-regions. Deciduous forest occurs on higher altitude along valleys across the mountain range, as within woodlands that are more abundant and contiguous in the north sub-region.

Unprotected HCVF and pCF covers 39\% of the forestland area and with almost equal shares on high productivity and low productivity sites (Fig. 3). The share of unprotected HCVF is greater on high (36\%) than on low productivity sites (20\%). In total across the study region, unprotected HCVF covers 532,000 ha (see Table 1). On high productivity sites, unprotected spruce forests dominate with an area of 216,000 ha of which 168,000 ha being HCVF. On low productivity sites, unprotected deciduous forests dominate with an area of 358,000 ha of which 98,000 ha being HCVF.

Across the entire study region, unprotected HCVF and pCF mainly occur in patches $>100$ ha, whereof $29 \%$ in large (>1000 ha) patches (Table 2, see also supplementary material table S2). A lower share occurs in smaller patches; $16 \%$ of the area is in patches $<10$ ha and $7 \%$ in patches $<1 \mathrm{ha}$. The largest contiguous areas are in the central and south sub-regions. The north sub-region has a low share $(7 \%)$ of large (> $1000 \mathrm{ha})$ patches of unprotected forests, and only the central sub-region has the largest share $(45 \%)$ in large patches (>1000 ha). The north and the far south sub-regions have the most even area distribution across patch size classes. The sub-regions show clear differences in distribution of unprotected $\mathrm{HCVF}$ and $\mathrm{pCF}$ (Fig. 4), with the north sub-region standing out with a small and scattered area and the central sub-region with concentrated and contiguous areas.

There are marked differences in forest ownership patterns among the sub-regions (Fig. 5, see also supplementary material table S2 and S3). Across the entire study region, NIPF and private incorporates own the largest share of unprotected high productivity forests, $42 \%$ and $38 \%$ respectively, across all patch size classes. The dominating patch size class is 100 to 1,000 ha for all sub-regions and ownership categories, with the exception of NIPF ownership in the northern subregion. However, private incorporates clearly dominate for the largest patch-size class, except in the far south subregion. For patches up to 100 ha, NIPF owners dominate in all sub-regions, and in the central and south sub-regions also in patches 100 to 1000 ha. The public ownership of unprotected forests is generally small.

With many different ownership polygons and a low average area of unprotected HCVF and pCF, the ownership structure is very complex in the far south sub-region in comparison with other sub-regions (Fig. 6). Of a total of 41,692 landowner polygons in the entire study region, 17,486 are in the far south with an average area of high productivity forestland per ownership polygon of $1.8 \mathrm{ha}$. In comparison, the corresponding average area in the south sub-region is 6.6 ha. The north sub-region is characterized by small and scattered forests whereas the central sub-region by larger and contiguous areas. The largest areas of unprotected HCVF and $\mathrm{pCF}$ are in the central and south sub-regions on private incorporate and NIPF ownership, with the former owner category mainly for patches larger than 1,000 ha. For smaller patches, NIPF owners dominate in all sub-regions and in particular in the central and south sub-regions. The public ownership of unprotected HCVF and pCF is small in comparison. NIPF and private incorporates own the majority of the unprotected $\mathrm{HCVF}$ and $\mathrm{pCF}$, with the latter category being the dominating owner of large patches.

\section{Discussion}

\section{High conservation values in the Scandinavian Mountains Green Belt}

Despite historical forestry and other land uses and cultures, high forest connectivity and continuity occurs widespread in the SMGB, but still with scattered gaps (Svensson et al. 2019; Mikusiński et al. 2021). Large and contiguous intact forest patches are concentrated in the area above the mountain forest border (Svensson et al. 2020a) and thus geographically connected to an over 3 million ha alpine environment forming a magnificent landscape with very high ecological and cultural values (Blicharska et al. 2017). Given the extensive transformation of forests and forest landscapes elsewhere across the Fennoscandian boreal forests (Heino et al. 2015; Kuuluvainen et al. 2012; Jonsson et al. 2019) and the severe loss of primary forests and intact forest landscapes in Europe (e.g. Sabatini et al. 2021), the SMGB stands out as a northern European mainland for intact forest landscapes. As for other clusters of old-growth and primary forest areas in Europe and globally, a high protection ambition is strongly motivated for the SMGB. This is also the key conclusion 

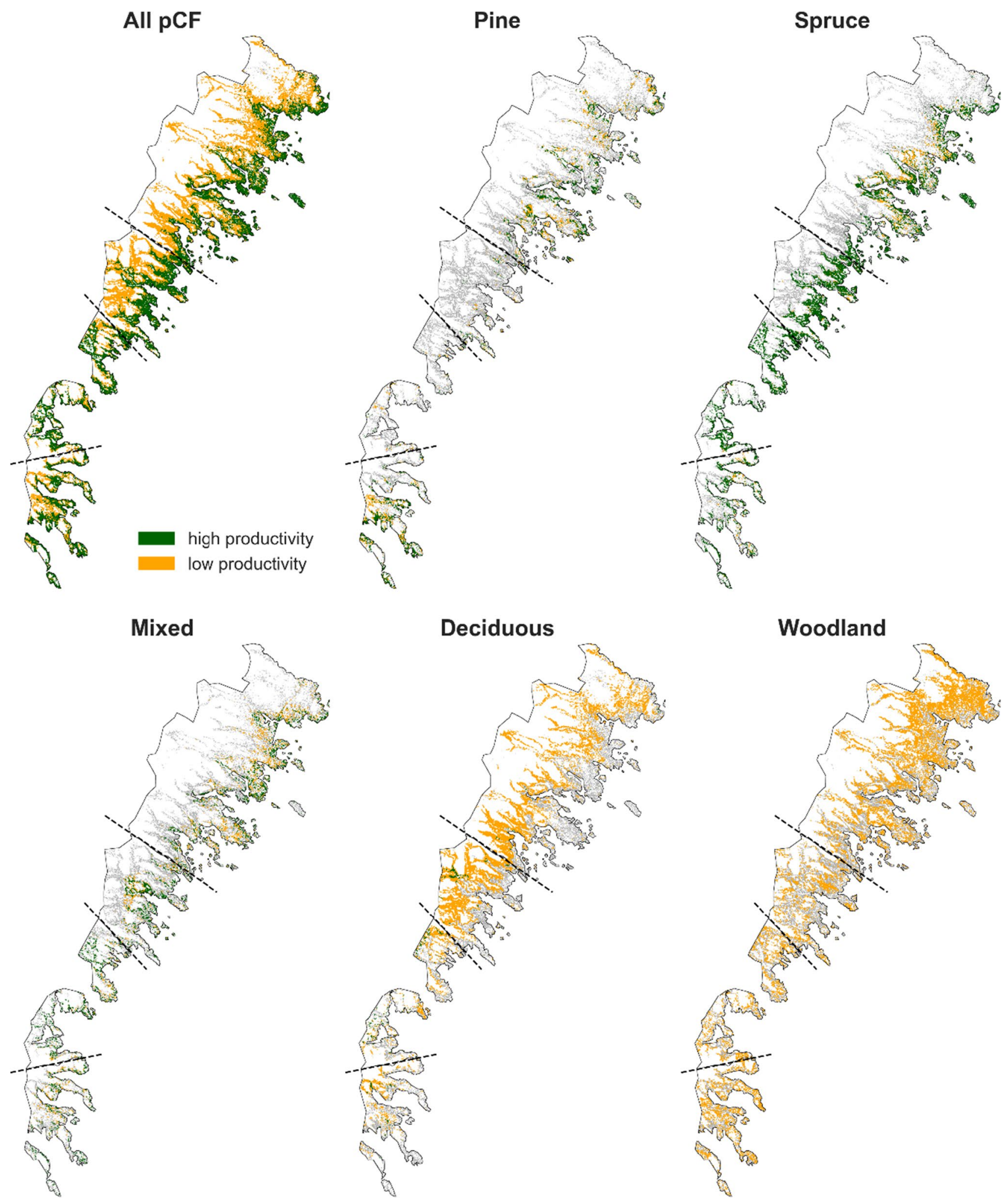

Fig. 2 Spatial distribution of all proxy continuity forests (pCF) and the distribution of pine, spruce, mixed and deciduous forest types, separated into on high productivity (green) and low productivity and woodland (yellow) sites. On the pine, spruce, mixed, deciduous and

woodland maps, the grey background shows the distribution of all pCF not falling into the focal category. The distribution is generalized through re-sampling for visual purpose. The study region is delineated by a grey line and the sub-regions by dashed lines 
Fig. 3 Non-pCF (forest loss), proxy continuity forest (pCF), unprotected high conservation value forest (HCVF), protected HCVF. (a) Proportion (\%) of high and low productivity sites of all forestland area, (b) area (in 1,000 ha) of pine, spruce, mixed and deciduous dominated forests on high productivity, and (c) on low productivity sites
Table 2 Area (in 1,000 ha) of unprotected proxy continuity forest including unprotected HCVF on high productivity sites, separated into patch-size classes and summarized for all forestland and for north, central, south and far south sub-regions

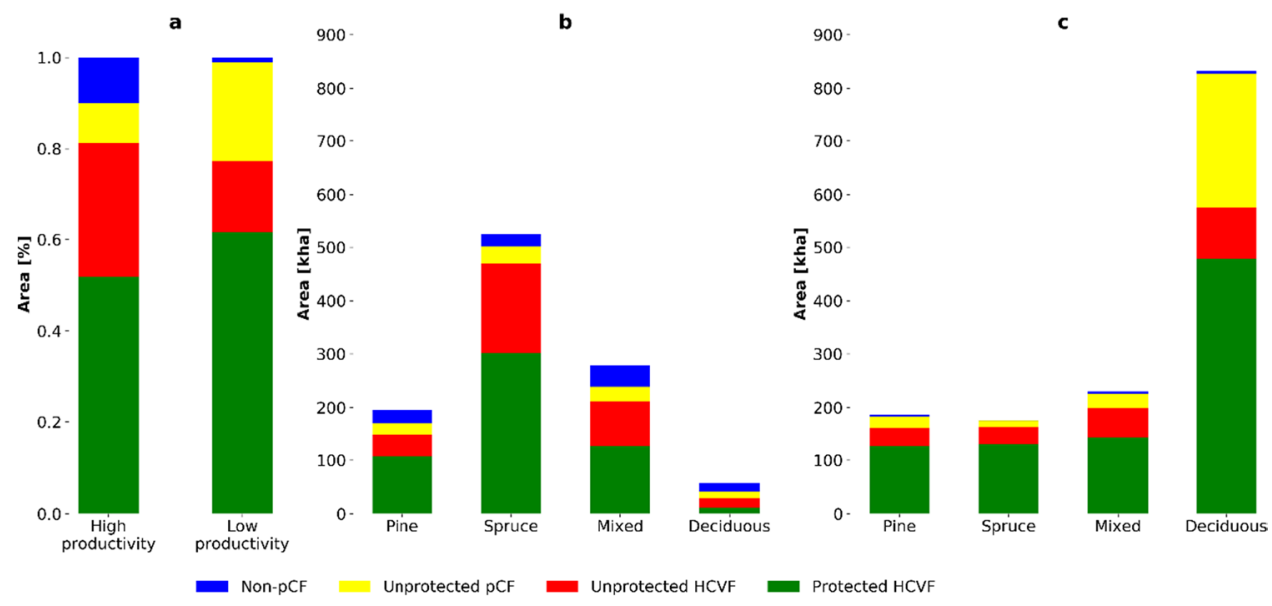

\begin{tabular}{lcclcrr}
\hline & $\leq 1$ ha & $1-<10$ ha & $10-<100$ ha & $100-<1000$ ha & $\geq 1000$ ha & Total \\
\hline All forestland & 28.5 & 33.8 & 68.7 & 143.9 & 113.5 & 388.4 \\
North & 11.2 & 10.4 & 21.5 & 30.8 & 5.2 & 79.1 \\
Central & 2.7 & 7.0 & 16.9 & 37.7 & 53.4 & 117.6 \\
South & 6.4 & 8.4 & 15.4 & 40.3 & 32.5 & 103.0 \\
Far south & 7.8 & 8.1 & 14.9 & 35.1 & 22.4 & 88.3 \\
\hline
\end{tabular}

Footnote: The minimum mapping unit was a 1 ha $(100 \times 100 \mathrm{~m})$ pixel that is dominated $(\geq 50 \%)$ by unprotected proxy continuity forest ( $\mathrm{pCF}$ ) on high productivity sites. Thus, the column $\leq 1$ ha includes fragmented forest patches that together cover $<50 \%$ of the $100 \times 100 \mathrm{~m}$ pixel estimated using the original $(10 \times 10 \mathrm{~m})$ data resolution in the recently launched forest policy inquiry (SOU 2020), which to fulfill the national commitment to conserve biodiversity (Aichi target \#11; CBD 2010) suggests to set aside the vast majority of the remaining not yet protected HCVF. Still, the SMGB partially contains fragmented forests with disrupted intactness, in particular in the southern parts, where also remaining unprotected forests occur in smaller patches separated into numerous polygons with a predominance of NIPF ownership.

The high conservation values of the SMGB are well known since a long time; indeed, the first national parks were established here already in 1909 (Statistics Sweden 2021). Overall, however, the current intactness is dependent both on the already protected and the not yet protected forests (Angelstam et al. 2020; Mikusiński et al. 2021). The recent (2020) inventory (Henriksson and Olsson 2020) identified more than 550,000 ha of unprotected HCVF, including areas (c. 200,000 ha; ibid.) adjacent to but below the mountain forest border. These forests extend eastwards into the inland region and have, thus, a potential to provide functional ecological network into the more transformed inland region. Thereby, identification of areas in the SMGB and in its vicinity that needs additional protection, as well as areas that potentially allow continued forest management and other land uses, is a needed planning basis for supporting multiple forest value chains. Although data and categorizations used are broad, our analyses are novel on the scale of the entire SMGB and provide urgently needed information into future national strategies for the SMGB and the mountain landscapes in general.

\section{Spared, shared and lost}

A long-term and diverse land-use history (e.g. Josefsson et al. 2010) has generated substantial heterogeneity and varying potentials for maintaining the intact forest landscape values across the whole SMGB. A significant proportion is already spared; the formally protected area constitutes close to $57 \%$ of all forestland with high and low productivity forests, woodlands and adjacent semi-open and open habitats, and the habitat network functionality is high (Angelstam et al. 2020; Mikusiński et al. 2021). The unprotected forests are currently debated (SOU 2020), of which our results show that 532,000 ha are documented as HCVF and 928,000 ha as pCF (i.e. not documented but potential HCVF). Of these totals, close to 400,000 ha are unprotected high productivity sites that may be available for some form of continued forestry. We argue that all HCVF need formal protection or voluntary conservation-targeted management strategies. 


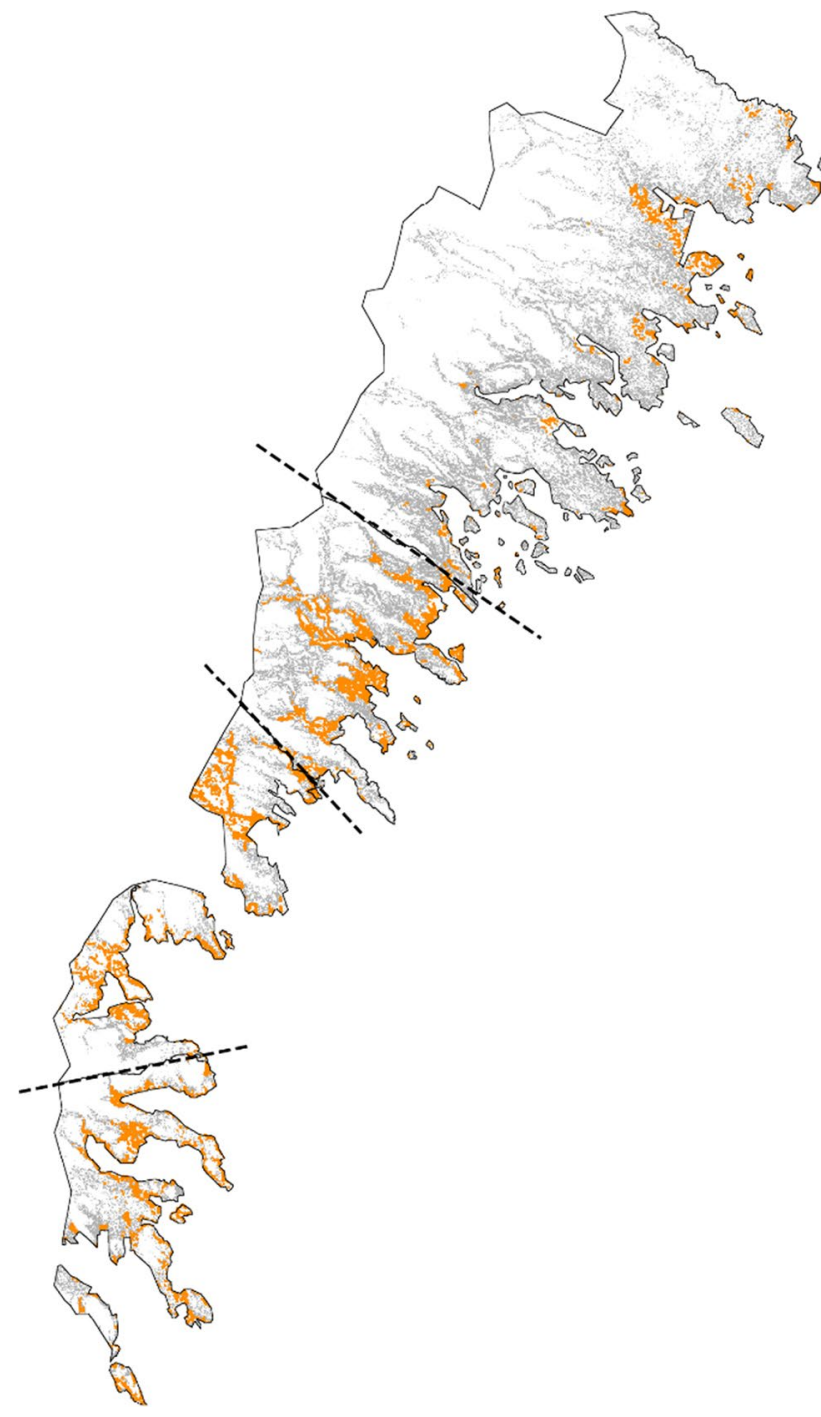

Fig. 4 The distribution of unprotected proxy continuity forest including unprotected HCVF on high productive sites. The distribution is generalized through re-sampling for visual purpose. The study region is delineated by a grey line and the sub-regions by dashed lines

Thus, substantially larger areas than what currently is formally protected should be spared, but other areas may be shared if the forest management methods will not compromise the intactness of the SMGB and the opportunities for other sustainable land-use interests and values.

We found that 190,000 ha forests have been clear-cut, corresponding to $7 \%$ of the total forestland area, $8 \%$ of the pCF area and 19\% of the high productivity forest area. Large clear-cuts on climatic constrained areas before the 1990s (Jonsson et al. 2019) have often created degraded lands (socalled fossilized clear-cuts). Still, the proportion of clear-cut forests is low which suggests that the regional importance of clear-cut forestry is limited (Jonsson et al. 2019). These areas can be considered as lost and do not contribute to intact forest landscape values. Here, we see two optional strategies. First, to either actively or passively promote forest restoration that by time add to the intact characteristics including, for example to allow natural regeneration and following succession after clear-cutting selectively favor deciduous tree species, and to favor trees with cavities and other biodiversity attributes in mature forests. Passive promotion embeds natural stand development, which would be in particular valuable for young deciduous-dominated forests that are critically missing in the Swedish boreal forest due to long-term active wild fire suppression and a forest management system that systematically favors coniferous stand development (Mikusiński et al. 2003).

In Fig. 7, we illustrate how green infrastructure, forest landscape restoration, continuous cover forestry, clear-cut forestry and integrative multi-functional landscape planning, can be approached to maintain the intact values of the SMGB. Conservation of biodiversity and provisioning of ecosystem services is focal in the green infrastructure concept (e.g. Slätmo et al. 2019). Already protected and unprotected $\mathrm{HCVF}$ as well as unprotected $\mathrm{pCF}$ that represent key components. Since some connectivity gaps in the SMGB have been documented (Svensson et al. 2020a), and because the area of suitable habitats needs to be increased (Mikusiński et al. 2021), there are reasons for considering forest and forest landscape restoration (cf. Mansourian 2018) in active or passive ways as discussed above. We also argue that continuous cover forestry can be promoted, in particular if viewed as an approach to manage forest ecosystems based on their inherent diverse values and premises (Mason et al. 1999). With the conservation of intact forest landscape values of the SMGB as a central goal, the range of land-use and management options calls for a comprehensive landscape approach (e.g. Arts et al. 2017) reflecting multiple values and balanced integrating and segregating approaches (Côté et al. 2010; Messier et al. 2019; Aggestam et al. 2020; Bollmann et al. 2020).

\section{Opportunities for multiple value chains supporting rural development}

The rich and diverse pool of natural resources and landscape values in the Swedish mountain region has generated a situation where multiple, diverging land-use claims overlap and where the combined land-use claims for economic, ecological and socio-cultural purposes substantially exceed the available land area (Svensson et al. 2020b). This implies a risk that some value chains dominate at the expense of others, and thus may lead to land-use conflicts and accelerating difficulties in land-use priority decisions to resolve them (Bjärstig et al. 2018). Building capacity for spatiotemporal and multi-objective resolution in sustainable landscape planning allows for diversified land-use for multiple value 


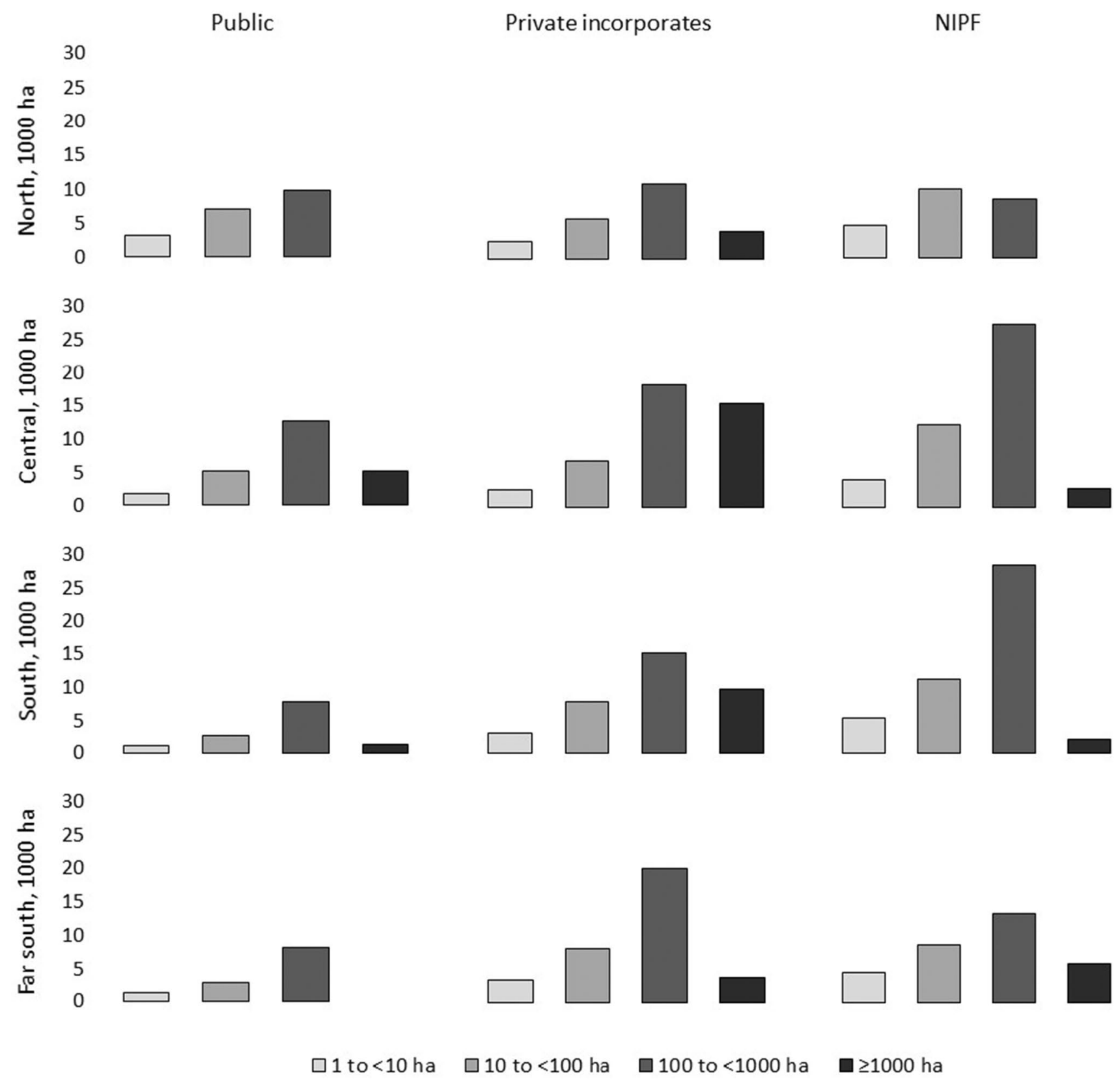

Fig. 5 Area (in 1,000 ha) of unprotected proxy continuity forests including unprotected $\mathrm{HCVF} \geq 1$ ha (see Table 2 ) on high productivity sites, separated into patch-size classes per ownership category for

chains (cf. Felton et al. 2020; Angelstam et al. 2020). Like in many other hinterland regions, sustainable local and regional development calls for value-chain avenues that are based on the broad spectrum of natural resources and landscape values with a strong local use and control (Chiasson et al. 2019; Sténs et al. 2016). Besides forestry, Sami culture including reindeer husbandry and recreation and tourism represents pronounced value chains (e.g. Fredman and Emmelin 2001; Jansson et al. 2015). north, central, south and far south sub-regions. Patch sizes $\geq 1,000$ ha for NIPF are patches that include more than one NIPF ownership polygon

It can be assumed that clear-cut forestry will occur also in the future, albeit on limited areas in respecting the generally low site fertility and lack of historical legitimacy, but foremost in respecting the conservation integrity of the SMGB. In the forest policy inquiry (SOU 2020), 240,000-ha forestland above the mountain forest border were identified as potentially available for continued forestry. Here, a minimum of overlap with core areas for nature conservation and other land use interests will have to be secured. In the context of other value chains, evidence is rapidly accumulating 
Fig. 6 Non-industrial private forest (NIPF) owners share (\%) per sub-region of area unprotected proxy continuity forest (pCF) and high conservation value forests (HCVF) and of number of owner polygons, i.e. separate administrative land units, left axis and average area per owner polygon, right axis. The number of owner polygons was extracted from Henriksson and Olsson (2020)

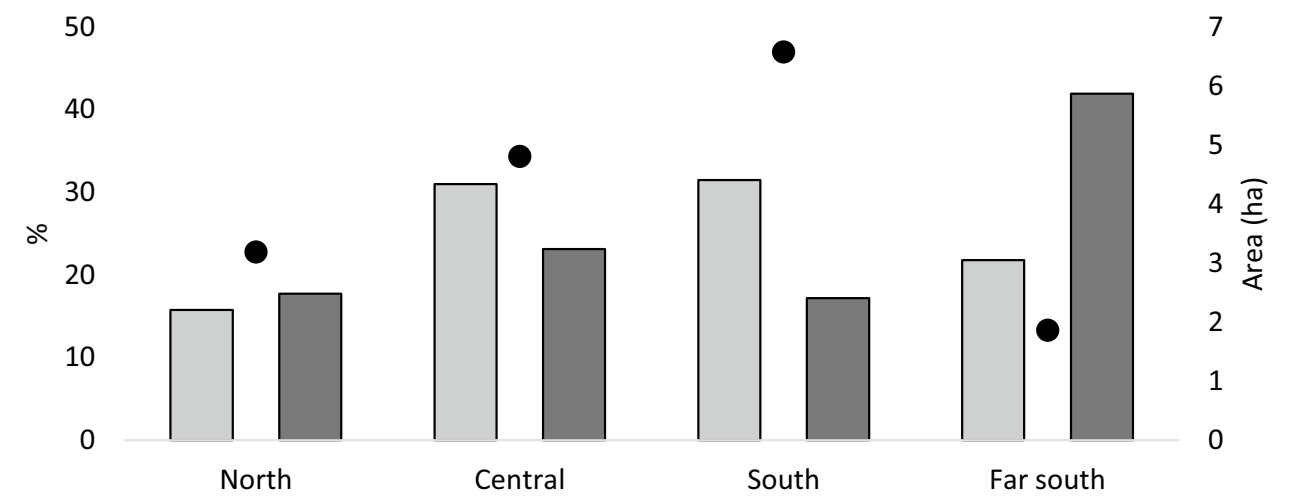

$\square$ Area share of not protected pCF and HCVF $\square$ Number share of owner polygons

- Average area per owner polygon

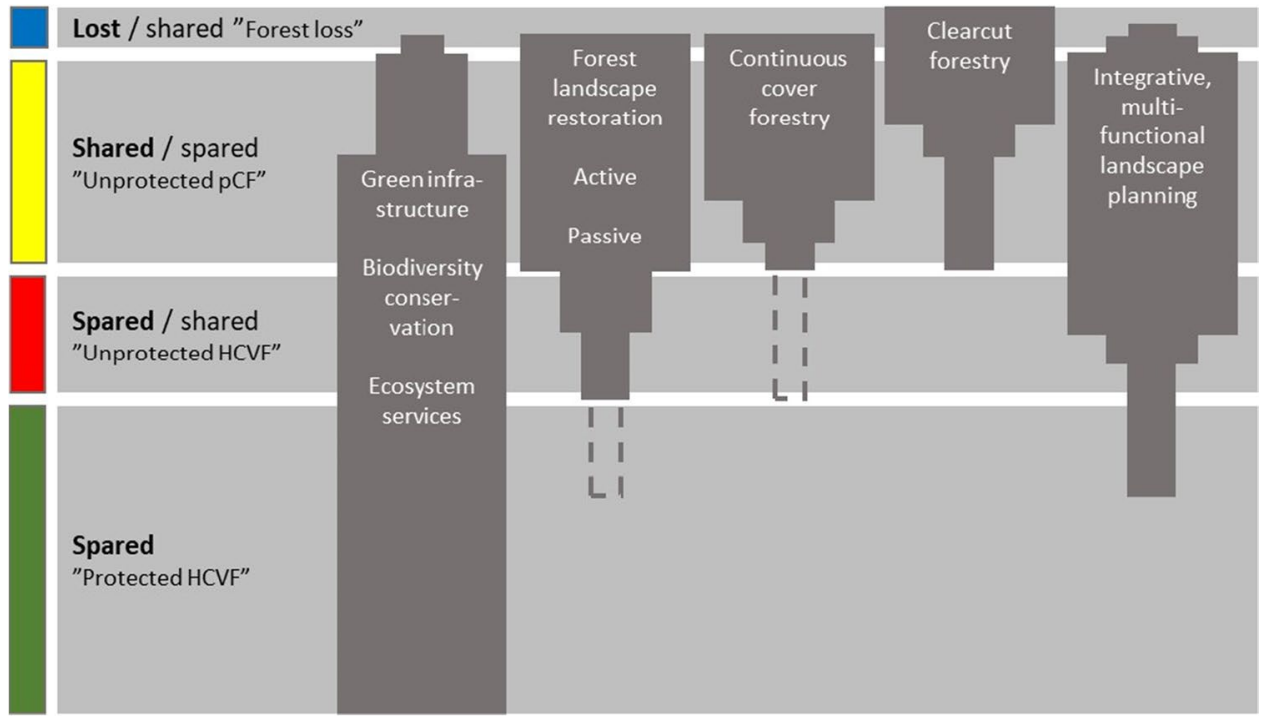

Fig. 7 Illustration on how approaches to green infrastructure, forest landscape restoration, continuous cover forestry, clear-cut forestry and integrative multi-functional landscape planning can be allocated among the forest-type categories and with respect to spared, shared and lost intactness. The vertical width of the light grey horizontal fields approximately equals their area proportions (Table 1). The horizontal width of the dark grey boxes represents full, moderate and minor extent and importance in each category. Dashed extensions of forest landscape restoration indicates management to favor biodiver-

on the favorable outcomes of continuous cover forestry in terms of economic viability (e.g. Nieminen et al. 2018), multifunctional capacity (e.g. Eyvindson et al. 2021), biological functions of soils (e.g. Kim et al. 2021) and with less negative impact on forest biodiversity (e.g. Peura et al. 2018). Since achieving multiple services and goods from forest environments is difficult at the local level, a diversification of management regimes at the broader landscape level supports a broader palette of biodiversity outcomes and ecosystems goods and services (e.g. Triviňo et al. 2017; Felton sity values if needed to secure intactness, and of continuous cover forestry to favor forest biodiversity that benefit from canopy thinning if needed (i.e. as an approach to management of forest ecosystems and not a wood biomass production system). The shared proportion in protected (minor extent) and unprotected (moderate extent) HCVF concerns other nature-based land use that does not negatively affect nature conservation values, and reindeer husbandry or wildlife tourism and recreation. The figure backgrounds how strategic, tactical and operational spatial planning can be developed

et al. 2020). Hence, a landscape perspective is needed for the forest management, which, so far however, has been arduous to promote and realize outside specifically designated areas such as the Sveaskog State forest company Ecoparks (Bergman and Gustafsson 2020).

Sapmi, the native land of the Sami people, is covering large areas in northern Europe including the SMGB, which contribute high profile indigenous values (Pape and Löffler 2012). The presence of a vital Sami culture with continued reindeer husbandry and grazing that maintains the openness 
and scenery in the mountain landscape is essential for provisioning of a very large range of specific ecosystem services (Jansson et al. 2015; Blicharska et al. 2017; Hedblom et al. 2020). Also, small-scale mountain farming has contributed to the overall biodiversity, multifaceted values, open and semi-open landscape character and to the amenity, recreation and tourism values of the Scandinavian Mountains, which are clearly mirrored in the "A Magnificent Mountain Landscape" national environmental objective (Swedish EPA 2007). It can be assumed that maintained intact forest landscapes are needed also for maintaining and supporting the cultural heritage and societal values of the SMGB. Furthermore, with reference to the intact forest landscapes and primary forest (Potapov et al. 2008a, b, 2017; FAO 2020), both terms embed the presence of historical land use and indigenous cultures.

By area cover and also locally in many places, outdoor recreation and tourism are dominant land uses with both nature-based and place-based facilities such as ski resorts (Fredman and Emmelin 2001; Svensson et al. 2020b). There are examples where incomes from tourism in regions with particularly high biodiversity values exceed those from wood biomass production (e.g. Czeszczewik et al. 2019). The touristic attractiveness of the Swedish mountain region is unquestionable and the process of change from intensive use of natural resources into "soft" sectors is established since a long time (Fredman and Emmelin 2001; Lundmark 2005). As tourism and recreation aspects are predicted to become an even more important value chain for rural development in the future (Jonsson et al. 2019), the need for spatial planning to accommodate uptake of local as well as visitor's perspectives on values and opportunities becomes emphasized.

In addressing opportunities and challenges for sustainable forest landscape management as a key component for rural development, the complex land-ownership situation needs to be considered. In this study, we have categorized landowners with a focus on NIPF owners and identified complexities and differences in the ownership structure of unprotected high productivity forests. The NIPF ownership requires particular attention in relation to sustainable rural development but also to green infrastructure, forest landscape restoration, continued forestry and planning. Here, a certain challenge lies with promoting ways forward to handle existing connectivity gaps in the southernmost part of the SMGB (Svensson et al. 2020a; Mikusiński et al. 2021) where most NIPF owners occur, where the ownership structure is the most complex and where there are limited opportunities in using public land as land-exchange compensation for further protection. To support preservation of the intact values of the SMGB in relation to sustainable development in the hinterland mountain region, policies, policy instruments and policy implementation must continue to develop. As one way forward, we suggest that voluntary agreements, such as conservation agreements under the Swedish Land Code (1970), could be more extensively applied in parallel to strict protection instruments. Conservation agreements are more nuanced formal regulations and may allow continued forest management if in accordance with biodiversity conservation targets or for favoring nature-based recreation or other socio-cultural vales, for which landowners are compensated economically, and can be further developed for multiple values including landscape perspectives and Sami people reindeer husbandry. The abovementioned State forest company Sveaskog Ecoparks (Bergman and Gustafsson 2020) is regulated through such agreements. There is an embedded capacity in policy instruments that relies on voluntary, dialogue and mutual agreement principles with the landowner (Widman and Bjärstig 2017), a capacity that is needed for successful protection of the intact values of the SMGB in the view of integrated approaches to sustainable local and regional development. We foresee that this study will help to direct further implementation based on what specific local values are at stake and who has control and vested interests given the natural and cultural capital.

\section{Conclusions}

The Swedish mountain region harbors high intact forest landscape and conservation values but also further values associated with multiple economic and socio-cultural value chains including those based on the indigenous Sami people culture. Despite a need to expand nature conservation, these multiple values challenges an overall strict protection approach. Using wall-to-wall land cover data, we provide a point of departure for maintaining intact forest landscape characteristics through strategic spatial planning of forestlands and future forest management. We show that in the SMGB, the fraction of actually clear-cut forest is very small and that the SMGB harbors a very high proportion of protected but also unprotected HCVF, located in a predominantly natural landscape context with woodlands and open alpine land-cover types. Forest management aimed at wood biomass production will continue, but sustainable approaches require increased use of continuous cover forestry and a sensitive implementation with respect to ownership and policy regulations.

This study contributes to evidence-based regional level green infrastructure planning, to the opportunities in applying a comprehensive and integrated sustainable landscape approach, and to exploring multiple opportunities for rural livelihood and regional development. This study also contributes to the current forest policy discussion in Sweden that suggests that the SMGB should be maintained as an intact forest landscape and thus as a cornerstone in the Swedish and EU nature conservation agenda. As such, we provide an 
illustrative case on the challenges to both ensure the integrity and values of an intact forest landscape of national and international significance, and support regional development. Clearly, a deeper stratification into, e.g. distribution of habitat types and specific values, is needed for future assessments, for example via a second-step field-based inventory at representative and specific segments of the study region.

Supplementary Information The online version contains supplementary material available at https://doi.org/10.1007/s10113-022-01881-8.

Acknowledgements We acknowledge data assistance by Birgitta Olsson, Swedish Environmental Protection Agency, and Wiebke Neumann, Swedish University of Agricultural Sciences, and comments on a revised version of the manuscript by Peter Bergman, Sveaskog, and Tommy Ek, Sveaskog and committee secretary for the 2020 forest policy inquiry.

Funding Open access funding provided by Swedish University of Agricultural Sciences. This study was funded by the Swedish Environmental Protection Agency, grant NV-03728-17, to Bengt Gunnar Jonsson and supported by FORMAS, grant 2017:1342, to Per Angelstam.

Open Access This article is licensed under a Creative Commons Attribution 4.0 International License, which permits use, sharing, adaptation, distribution and reproduction in any medium or format, as long as you give appropriate credit to the original author(s) and the source, provide a link to the Creative Commons licence, and indicate if changes were made. The images or other third party material in this article are included in the article's Creative Commons licence, unless indicated otherwise in a credit line to the material. If material is not included in the article's Creative Commons licence and your intended use is not permitted by statutory regulation or exceeds the permitted use, you will need to obtain permission directly from the copyright holder. To view a copy of this licence, visit http://creativecommons.org/licenses/by/4.0/.

\section{References}

Aggestam F, Konczal A, Sotirov M, Wallin I, Paillet Y, et al. (2020) Can nature conservation and wood production be reconciled in managed forests? A review of driving factors for integrated forest management in Europe. Journal of Environmental Management 268, art. no. 110670. https://doi.org/10.1016/j.jenvman. 2020. 110670

Ahlcrona E, Giljam C, Wennberg, S (2017) Kartering av kontinuitetsskog i boreal region. Metria $\mathrm{AB}$ på uppdrag av naturvårdsverket, Stockholm, Sweden. 79 pp (In Swedish)

Angelstam P, Manton M (2021) Effects of forestry intensification and conservation on green infrastructures: a spatio-temporal evaluation in Sweden. Land 10:531. https://doi.org/10.3390/land100505 31

Angelstam P, Axelsson R, Elbakidze M, Laestadius L, Lazdinis M et al (2011) Knowledge production and learning for sustainable forest management: European regions as a time machine. Forestry 84(5):581-596. https://doi.org/10.1093/forestry/cpr048

Angelstam P, Manton M, Green M, Jonsson BG, Mikusinski G et al (2020) Sweden does not meet agreed national and international forest biodiversity targets: a call for adaptive landscape planning. Landsc Urban Plan 202:103838. https://doi.org/10.1016/j.landu rbplan.2020.103838
Angelstam P, Manton M, Yamelynets T, Fedoriak M, Albulescu A-C et al (2021) Maintaining natural and traditional cultural green infrastructures across Europe: learning from historic and current landscape transformations. Landscape Ecol 36:637-663. https:// doi.org/10.1007/s10980-020-01161-y

Anon. (2017) Skogliga värdekärnor i Sverige - sammanfattande beskrivning av dataurval och nuläge 2015-2016. Bilaga 2a till Naturvårdsverkets och Skogsstyrelsens redovisning av regeringsuppdrag om Värdefulla skogar, 2017-01-30 (In Swedish)

Arts B, Buizer M, Horlings L, Ingram V, van Osten C et al (2017) Landscape approaches: a state-of-the-art review. The Annual Review of Environment and Resources 42:439-463. https://doi. org/10.1146/annurev-environ-102016-060932

Bar-on Y, Phillips R, Milo R (2018) The biomass distribution on earth. PNAS 115(25):6506-6511. https://doi.org/10.1073/pnas.17118 42115

Bengtsson J, Angelstam P, Elmqvist T, Emanuelsson U, Folke C et al (2003) Reserves, resilience and dynamic landscapes. Ambio 32:389-396. https://doi.org/10.1579/0044-7447-32.6.389

Bergman P, Gustafsson L (2020) Ecoparks - Forest landscapes in Sweden with emphasis on biodiversity conservation and recreation. P. 369-378. In: Krumm, F.; Schuck, A.; Rigling, A. (eds), 2020: How to balance forestry and biodiversity conservation - a view across Europe. European Forest Institute. https://doi.org/10. 16904/envidat. 196

Betts MG, Phalan BT, Wolf C, Baker SC, Messier C et al (2021) Producing wood at least cost to biodiversity: integrating Triad and sharing-sparing approaches to inform forest landscape management. Biol Rev. https://doi.org/10.1111/brv.12703

Bjärstig T, Thellbro C, Zachrisson A, Svensson J (2018) Implementing collaborative planning in the Swedish mountains - the case of Vilhelmina Model Forest. WIT Transactions on Ecology and the Environment: Sustainable Development and Planning, pp. 78-796. Southhampton, WIT Press. http://urn.kb.se/resolve?urn= urn:nbn:se:umu:diva-146723

Blicharska M, Smithers RJ, Hedblom M, Hedenås H, Mikusiński G et al (2017) Shades of grey challenge practical application of the cultural ecosystem services concept. Ecosyst Serv 23:55-70. https://doi.org/10.1016/j.ecoser.2016.11.014

Blumroeder JS, Burova N, Winter S, Goroncy A, Hobson PR, et al. (2019) Ecological effects of clearcutting practices in a boreal forest (Arkhangelsk Region, Russian Federation) both with and without FSC certification. Ecological Indicators, 106(105461). https://doi.org/10.1016/j.ecolind.2019.105461

Bollmann K, Kraus D, Paillet Y, Jonsson BG, Gustafsson L, et al. (2020) A unifying framework for the conservation of biodiversity in multi-functional European forests. In Krumm F, Schuck A, Rigling A (eds.) How to balance forestry and biodiversity conservation - a view across Europe, pp. 27-45. European Forest Institute; Swiss Federal Institute for Forest, Snow and Landscape Research, Birmensdorf

CBD (2010) Convention on biological diversity strategic plan for biodiversity 2011-2020 and the Aichi targets. Convention on Biological Diversity, Montreal. Available from https://www.cbd.int/sp/ targets/. (Accessed March 2019)

CBD (2020) Updated zero draft of the post-2020 global biodiversity framework. Available from https://www.cbd.int/article/zero-draftupdate-august-2020 (Accessed June 2021)

Chiasson G, Angelstam P, Axelsson R, Doyon F (2019) Towards collaborative forest planning in Canadian and Swedish hinterlands: different institutional trajectories? Land Use Policy 83:334-345. https://doi.org/10.1016/j.landusepol.2019.02.015

Côté P, Tittler R, Messier C, Kneeshaw DD, Fall A et al (2010) Comparing different forest zoning options for landscape-scale management of the boreal forest: possible benefits of the TRIAD. For 
Ecol Manage 259(3):418-427. https://doi.org/10.1016/j.foreco. 2009.10.038

Curtis PG, Slay CM, Harris NL, Tyukavina A, Hansen MC (2018) Classifying drivers of global forest loss. Science 361(6407):11081111. https://doi.org/10.1126/science.aau3445

Czeszczewik D, Ginter A, Mikusiński G, Pawłowska A, Kałuża H et al (2019) Birdwatching, logging and local economy in the Białowieża Forest, Poland. Biodivers Conserv 28:2967-2975. https://doi.org/10.1007/s10531-019-01808-6

EU (2020) Biodiversity Strategy for 2030. Bringing nature back into our lives. https://ec.europa.eu/environment/strategy/biodiversitystrategy-2030 (accessed June 2021)

European Commission (2013) Communication from the Commission to the European Parliament, the Council, The European Economic and Social Committee and the Committee of the Regions: Green Infrastructure (GI) -Enhancing Europe's Natural Capital: COM/2013/0249: https://eur-lex.europa.eu

Eyvindson K, Duflot R, Triviňo M, Blattert C, Potterf M, et al. (2021) High boreal forest multifunctionality requires continuous cover forestry as a dominant management. Land Use Policy 100(104918). https://doi.org/10.1016/j.landusepol.2020.104918

FAO (2020) General forest resources assessment (FRA) 2020. Terms and definitions. Forest resources assessment working paper 188. Food and Agriculture Organization of the United Nations. 26 pp.

Felton A, Löfroth T, Angelstam P, Gustafsson L, Hjälten J et al (2020) Keeping pace with forestry: multi-scale conservation in a changing production forest matrix. Ambio 49(5):1050-1064. https://doi. org/10.1007/s13280-019-01248-0

Fredman P, Emmelin L (2001) Wilderness purism, willingness to pay and management preferences: a study of Swedish mountain tourists. Tour Econ 7(1):5-20. https://doi.org/10.5367/0000000011 01297702

Hämäläinen A, Strengbom J, Ranius T (2019) Low-productivity boreal forests have high conservation value for lichens. Journal of Applied Ecology. https://doi.org/10.1111/1365-2664.13509

Hedblom M, Hedenås H, Knez I, Blicharska M, Adler S et al (2020) Indicators for landscape perception: a model linking physical monitoring data with perceived landscape properties. Landsc Res 45:179-192. https://doi.org/10.1080/01426397.2019.1611751

Hedenås H, Christensen P, Svensson J (2016) Changes in vegetation cover and composition in the Swedish mountain region. Ecological Monitoring and Assessment 188:452. https://doi.org/10.1007/ s10661-016-5457-2

Heino M, Kummu M, Makkonen M, Mulligan M, Verburg PH et al (2015) Forest loss in protected areas and intact forest landscapes: a global analysis. PLOS ONE 10(10). https://doi.org/10.1371/journ al.pone. 0138918

Henriksson S, Olsson B (2020) Kunskapssammanställning fjällnära skog. Redovisning av underlag till Skogsutredningen 2019. Naturvårdsverket och Skogsstyrelsen, 2020-02-14. Dnr. NV-07994-19. (In Swedish)

Holmgren E, Holmgren L, Lidestav G (2007) Comparison of harvesting and business activities of non-shareholders and shareholders in a forest common in Västerbotten. Sweden Scandinavian Journal of Forest Research 22(6):582-592. https://doi.org/10.1080/02827 580701618769

Jansson R, Nilsson C, Keskitalo EHC, Vlasova T, Sutinen ML et al (2015) (2015) Future changes in the supply of goods and services from natural ecosystems: prospects for the European north. Ecol Soc 20(3):32. https://doi.org/10.5751/ES-07607-200332

Jones KR, Venter O, Fuller RA, Allan JR, Maxwell SL et al (2018) One-third of global protected land is under intense human pressure. Science 360:788-791. https://doi.org/10.1126/science.aap95 65
Jonsson BG, Svensson J, Mikusiński G, Manton M, Angelstam P (2019) European Union's last intact forest landscape is at a value chain crossroad between multiple use and intensified wood production. Forests 10:564. https://doi.org/10.3390/f10070564

Josefsson T, Gunnarsson B, Liedgran L, Bergman I, Östlund L (2010) Historical human influence on forest composition and structure in boreal Fennoscandia. Can J for Res 40:872-884. https://doi. org/10.1139/X10-033

Kim S, Axelsson EP, Girona MM, Senior JK (2021) Continuous-cover forestry maintains soil fungal communities in Norway spruce dominated boreal forests. For Ecol Manage 480:118659. https:// doi.org/10.1016/j.foreco.2020.118659

Kleinschroth F, Garcia C, Ghazoul J (2019) Reconciling certification and intact forest landscape conservation. Ambio 48(2):153-159. https://doi.org/10.1007/s13280-018-1063-6

Kuuluvainen T, Hofgaard A, Aakala T, Jonsson BG (2017) North Fennoscandian mountain forests: History, composition, disturbance dynamics and the unpredictable future. For Ecol Manage 385:140-149. https://doi.org/10.1016/j.foreco.2016.11.031

Kuuluvainen T, Tahvonen O, Aakala T (2012) Even-aged and uneven-aged forest management in boreal Fennoscandia: A review. Ambio, 41(7):720-737. https://www.jstor.org/stable/23322896

Land Code (1970) Swedish land code. Jordabalk 1970:994, updated to SFS 2020:919 (In Swedish)

Lundmark L (2005) Economic restructuring into tourism in the Swedish mountain range. Scand J Hosp Tour 5(1):23-45. https://doi. org/10.1080/15022250510014273

Mansourian S (2018) In the eye of the beholder: reconciling interpretations of forest landscape restoration. Land Degrad Dev 29:2888 2898. https://doi.org/10.1002/ldr.3014

Mason B, Kerr G, Simpson J (1999) What is continuous cover forestry? UK Forestry Commission information note, October 1999. www. forestreserachgov.uk (FCIN29)

Messier C, Bauhus J, Doyon F, Maure F, Sousa-Silva R et al (2019) The functional complex network approach to foster forest resilience to global changes. Forest Ecosystems 6(1):1-16. https://doi.org/10. 1186/s40663-019-0166-2

Mikoláš M, Ujházy K, Jasík M, Wiezik M, Gallay I et al (2019) Primary forest distribution and representation in a Central European landscape: results of a large-scale field-based census. For Ecol Manage 449:117466. https://doi.org/10.1016/j.foreco.2019. 117466

Mikusiński G, Angelstam P, Sporrong U (2003) Distribution of deciduous stands in villages located in coniferous forest landscapes in Sweden. Ambio 32:520-526. https://doi.org/10.1579/0044-744732.8.520

Mikusiński G, Bubnicki JW, Churski M, Czeszczewik D, Walankiewicz W et al (2018) Is the impact of loggings in the last primeval lowland forest in Europe underestimated? The conservation issues of Białowieża Forest. Biol Cons 227:266-274. https://doi.org/10. 1016/j.biocon.2018.09.001

Mikusiński G, Orlikowska EH, Bubnicki JW, Jonsson BG, Svensson J (2021) Strengthening the network of high conservation value forests in boreal landscapes. Front Ecol Evol 8:595730. https:// doi.org/10.3389/fevo.2020.595730

Nieminen M, Hokka H, Laiho R, Juutinen A, Ahtikoski A et al (2018) Could continuous cover forestry be an economically and environmentally feasible management option on drained boreal peatlands? For Ecol Manage 424:78-84. https://doi.org/10.1016/j. foreco.2018.04.046

Pape R, Löffler J (2012) Climate change, land use conflicts, predation and ecological degradation as challenges for reindeer husbandry in northern Europe: what do we really know after half a century of research? Ambio 41:421-434. https://doi.org/10.1007/ s13280-012-0257-6 
Peura M, Burgas D, Eyvindson K, Repo A, Mönkkönen M (2018) Continuous cover forestry is a cost-efficient tool to increase multifunctionality of boreal production forests in Fennoscandia. Biol Cons 217:104-112. https://doi.org/10.1016/j.biocon.2017.10.018

Pickett S, Cadenasso M (2018) Landscape ecology: spatial heterogeneity in ecological systems. Science 269:331-334. http://www.jstor. org/stable/2888265

Potapov P, Hansen MC, Laestadius L, Turubanova S, Yaroshenko A et al (2017) The last frontiers of wilderness: tracking loss of intact forest landscapes from 2000 to 2013. Sci Adv 3:1-13. https://doi. org/10.1126/sciadv. 1600821

Potapov P, Yaroshenko A, Turubanova S, Dubinin M, Laestadius L et al (2008) Mapping the world's intact forest landscapes by remote sensing. Ecology and Society 13:51. http://www.ecologyandsocie ty.org/vol13/iss2/art51/

Potapov P, Yaroshenko A, Turubanova S, Dubinin M, Laestadius L et al (2008) Mapping the world's intact forest landscapes by remote sensing. Ecology and Society 13(51). http://www.ecologyandsocie ty.org/vol13/iss2/art51/

Roberge J-M (2018) Vetenskapligt kunskapsunderlag för nyckelbiotopsinventeringen i nordvästra Sverige. Skogsstyrelsen rapport 11. $99 \mathrm{pp}$ (In Swedish)

Sabatini FM, Burrascano S, Keeton WS, Levers C, Lindner M et al (2018) Where are Europe's last primary forests? Divers Distrib 24(10):1426-1439. https://doi.org/10.1111/ddi.12778

Sabatini FM, Keeton WS, Lindner M, Svoboda M, Verkerk PJ et al (2020) Protection gaps and restoration opportunities for primary forests in Europe. Divers Distrib 00:1-17. https://doi.org/10.1111/ ddi. 13158

Sabatini FM, Bluhm H, Kun Z, Aksenov D, Atauri JA, et al. (2021) European primary forest database v2.0. Scientific Data 8:220. https://doi.org/10.1038/s41597-021-00988-7

Seedre M, Felton A, Lindbladh M (2018) What is the impact of continuous cover forestry compared to clearcut forestry on standlevel biodiversity in boreal and temperate forests? A systematic review protocol. Environmental Evidence. https://doi.org/10.1186/ s13750-018-0138-y

Slätmo E, Nilsson K, Turunen E (2019) Implementing green infrastructure in spatial planning in Europe. Land 8:62. https://doi.org/10. 3390/land8040062

SOU (2020) Stärkt äganderätt, flexibla skyddsformer och naturvård i skogen. Betänkande av Skogsutredningen 2019, del 2. Statens Offentliga Utredningar, Stockholm 2020. (In Swedish)

Statistics Sweden (2019) Land use in Sweden. $7^{\text {th }}$ edition. SCB, Statistiska centralbyrån, Stockholm. Available at www.scb.se URN:NBN:SE:SCB-2019- MI03BR1901 (in Swedish)

Statistics Sweden (2021) Status 2020-12-31. Statistics Sweden and Swedish Environmental Protection Agency. MI 41 2020A01. Available at www.scb.se URN:NBN:SE:SCB-2021: MI41SM2101 (in Swedish)

Sténs A, Bjärstig T, Nordström EM, Sandström C, Fries C, Johansson $J$ (2016) In the eye of the stakeholder: the challenges of governing social forest values. Ambio 45:587-599. https://doi.org/10.1007/ s13280-015-0745-6

Svensson J, Andersson J, Sandström P, Mikusiński G (2019) Jonsson BG (2018) Landscape trajectory of natural boreal forest loss as an impediment to green infrastructure. Conserv Biol 33(1):152-163. https://doi.org/10.1111/cobi.13148

Svensson J, Bubnicki JW, Jonsson BG, Andersson J, Mikusiński G (2020a) Conservation significance of intact forest landscapes in the Scandinavian mountains green belt. Landscape Ecol 35:21132131. https://doi.org/10.1007/s10980-020-01088-4

Svensson J, Neumann W, Bjärstig T, Zachrisson Thellbro C (2020b) Landscape approaches to sustainability - aspects of conflict, integration and synergy in national public land-use interests. Sustainability 12(12):5113. https://doi.org/10.3390/su12125113

Swedish Forest Agency (1991). Skogsstyrelsens författningssamling SKSFS 1991:3, förordning om gränsen för fjällnära skog. ISSN 0347-5212

Swedish EPA (2007) Swedish Environmental Protection Agency. Storslagen fjällmiljö. Underlagsrapport till fördjupad utvärdering av miljömålsarbetet (In Swedish)

Swedish EPA (2019) Nationella Marktäckedata (NMD). Swedish Environmental Protection Agency. Available online at https://www. naturvardsverket.se/Samar-miljon/Kartor/Nationella-Marktacked ata-NMD/ (accessed December 2020) (In Swedish)

Thom D, Golivets M, Edling L, Meigs GW, Gourevitch JD et al (2019) (2019) The climate sensitivity of carbon, timber, and species richness covaries with forest age in boreal-temperate North America. Glob Change Biol 25:2446-2458. https://doi.org/10.1111/gcb. 14656

Triviňo M, Pohjanmies T, Mazziotta A, Juutinen A, Podkopaev D et al (2017) Optimizing management to enhance multifunctionality in a boreal forest landscape. J Appl Ecol 54(1):61-70. https://doi.org/ $10.1111 / 1365-2664.12790$

UN (2019) United Nations decade on ecosystem restoration (20212030). Resolution adopted by the General Assembly on 1 March 2019, Seventy-third session, Agenda item 14. A/RES/73/284

Venier LA, Walton R, Thompson ID, Arsenault A, Titus BD (2018) A review of the intact forest landscape concept in the Canadian boreal forest: its history, value, and measurement. Environ Rev 26(4):369-377. https://doi.org/10.1139/er-2018-0041

Venter O, Sanderson EW, Magrach A, Allan JR, Beher J et al (2016) Sixteen years of change in the global terrestrial human footprint and implications for biodiversity conservation. Nat Commun 7:12558. https://doi.org/10.1038/ncomms12558

Ward M, Saura S, Williams B, Ramirez-Delgado JP, Arafeh-Dalmau N et al (2020) Just ten percent of the global terrestrial protected area network is structurally connected via intact land. Nat Commun 11(4563). https://doi.org/10.1038/s41467-020-18457-x

Watson JEM, Evans T, Venter O, Williams B, Tulloch A et al (2018) The exceptional value of intact forest ecosystems. Nature Ecology and Evolution 2:599-610. https://doi.org/10.1038/ s41559-018-0490-x

Widman U, Bjärstig T (2017) Protecting forests' social values through partnerships. Scand J for Res 32(7):633-644. https://doi.org/10. $1080 / 02827581.2017 .1342860$

Zanotti L, Knowles N (2020) Large intact forest landscapes and inclusive conservation: a political ecological perspective. Journal of Political Ecology 27(1):539-557. https://doi.org/10.2458/v27i1. 23165

Publisher's Note Springer Nature remains neutral with regard to jurisdictional claims in published maps and institutional affiliations. 